\title{
The effect of composition drift and copolymer microstructure on mechanical bulk properties of styrene-methyl acrylate emulsion copolymers
}

\section{Citation for published version (APA):}

Schoonbrood, H. A. S., Brouns, H. M. G., Thijssen, H. A., Herk, van, A. M., \& German, A. L. (1995). The effect of composition drift and copolymer microstructure on mechanical bulk properties of styrene-methyl acrylate emulsion copolymers. Macromolecular Symposia, 92, 133-156. https://doi.org/10.1002/masy.19950920113

DOI:

10.1002/masy. 19950920113

Document status and date:

Published: 01/01/1995

\section{Document Version:}

Publisher's PDF, also known as Version of Record (includes final page, issue and volume numbers)

\section{Please check the document version of this publication:}

- A submitted manuscript is the version of the article upon submission and before peer-review. There can be important differences between the submitted version and the official published version of record. People interested in the research are advised to contact the author for the final version of the publication, or visit the DOI to the publisher's website.

- The final author version and the galley proof are versions of the publication after peer review.

- The final published version features the final layout of the paper including the volume, issue and page numbers.

Link to publication

\footnotetext{
General rights

- You may freely distribute the URL identifying the publication in the public portal. follow below link for the End User Agreement:

www.tue.nl/taverne

\section{Take down policy}

If you believe that this document breaches copyright please contact us at:

openaccess@tue.nl

providing details and we will investigate your claim.
}

Copyright and moral rights for the publications made accessible in the public portal are retained by the authors and/or other copyright owners and it is a condition of accessing publications that users recognise and abide by the legal requirements associated with these rights.

- Users may download and print one copy of any publication from the public portal for the purpose of private study or research.

- You may not further distribute the material or use it for any profit-making activity or commercial gain

If the publication is distributed under the terms of Article $25 \mathrm{fa}$ of the Dutch Copyright Act, indicated by the "Taverne" license above, please 


\section{THE EFFECT OF COMPOSITION DRIFT AND COPOLYMER MICROSTRUCTURE ON MECHANICAL BULK PROPERTIES OF STYRENE-METHYL ACRYLATE EMULSION COPOLYMERS}

Harold A.S. Schoonbrood, Harry M.G. Brouns, Henk A. Thijssen, Alex M. Van Herk, Anton L. German*

Laboratory of Polymer Chemistry, Eindhoven University of Technology, PO box 513, 5600 MB Eindhoven, The Netherlands

Abstract: In order to determine the influence of composition drift and copolymer microstructure on the mechanical bulk properties of styrene methyl acrylate copolymers, several copolymers were produced by emulsion copolymerization. Three different average compositions were used. By performing the copolymerizations under batch and semicontinuous conditions with two different monomer addition strategies (starved conditions and optimal addition) it was possible to control composition drift and to produce copolymers with different microstructures (chemical composition distributions). All these copolymers were processed in a way that ensured that the original particle structure was lost before the polymers were tested. It was found that composition drift had an influence on the mechanical properties (Young's modulus, maximum stress, elongation at break). This influence could be understood very well on the basis of present knowledge about structure-mechanical properties relationships. In the case of homogeneous copolymers maximum stress and elongation at break are dependent on the molecular weight, and only weakly dependent on the chemical composition, and Young's modulus is independent of chemical composition and molecular weight in the range of compositions investigated, as expected. In the case of heterogeneous copolymers, the influence of copolymer microstructure on Young's modulus, maximum stress and elongation at break is very large. Depending on the extent of control of composition drift during the polymerizations, phase separation was observed in the processed polymers, and the presence of a rubber phase affected the properties profoundly. 


\section{INTRODUCTION}

Considerable effort has been put into research on (emulsion) copolymerization in order to elucidate the processes that govern the intramolecular and intermolecular microstructure of copolymers. Similarly, a lot of work has been dedicated to influencing the microstructure of the copolymers by controlling the addition rates of the monomers fed to the reactor during semicontinuous (emulsion) copolymerizations (Refs, 1-8). However, understanding the way a particular microstructure comes about is not enough, if the final aim is producing an emulsion copolymer with specific properties (Ref. 9). It is necessary to understand the correlation between microstructure and properties as well. Emulsion polymers are very often applied in films (Ref. 10), and it is therefore useful to look at film forming properties and final film properties. These reflect both particle morphology (for instance core-shell structures (Refs. 11-13), and bulk properties of the polymers in the particles. The particle morphology can either be due to composition drift or be purposely brought about by seeded polymerization (Ref. 14). The properties of the films are studied by casting films from the latices and looking directly at the structure and the properties of the films (Refs. 15-17). For the final properties of the films the bulk properties of the polymers in the particles are equally important (Ref. 10). In this investigation the aim is revealing the influence of composition drift through the chemical composition distribution (CCD) on the mechanical bulk properties of styrene - methyl acrylate emulsion copolymers. Therefore a series of copolymers with different CCDs has been prepared by applying different monomer addition strategies. This was reported on in an earlier publication (Ref. 18).

\section{EXPERIMENTAL}

Preparation of the Emulsion Copolymers

We applied three different average compositions, namely 80,50 and $25 \mathrm{~mol} \%$ of styrene (S). S and methyl acrylate (MA) (both p.a., Merck) were distilled before use. Reaction temperature was $50{ }^{\circ} \mathrm{C}$, final polymer to water ratio was $0.2 \mathrm{~g} / \mathrm{g}$. Sodium persulfate was used as initiator, sodium bicarbonate as buffer, n-dodecyl mercaptan (NDM) as chain transfer agent (all p.a., Merck), and sodium dodecyl sulfate (Fluka, 99\%) as emulsifier. For each composition we prepared the polymers batch-wise, or semicontinuously under starved conditions with an addition time of 8 hours (without using a seed latex), or with 
the so-called optimal addition method (Refs. 4,5,18) with a seed latex. The polymers that are made semicontinuously are homogeneous with regards to chemical composition distribution (CCD). We made some further attempts to make a copolymer with predefined controlled heterogeneity, i.e., a copolymer that is not homogeneous in composition, but has a CCD with predetermined broadness profile, as was reported on before (Ref. 18). Although our attempts did not lead to the specific desired CCD, they did result in three copolymers with interesting CCDs. Details of the recipes were given before (Ref. 18). Since it is known that the molecular weight distribution (MWD) can have a significant influence on the properties as well (Ref. 8), we added a chain transfer agent to make sure that the method of preparing the polymers (i.e., batch-wise or semicontinuously) did not have a significant influence on the molecular weight distribution (MWD). It was shown that there was indeed no significant effect of addition strategy on MWD.

\section{Processing of the Polymers}

After preparation the polymer latices were dialysed against deionized water to remove unreacted initiator, buffer and emulsifier. Subsequently the latices were coagulated by adding $6 \mathrm{ml}$ of a $0.5 \mathrm{M}$ aluminum nitrate solution $\left(\mathrm{Al}\left(\mathrm{NO}_{3}\right)_{3} \cdot 9 \mathrm{H}_{2} \mathrm{O}\right.$, Merck, cryst. pure) to 11 of latex, at a rate of $1 \mathrm{ml}$ per minute under continuous stirring. The copolymers were then washed three times with $1 \mathrm{l}$ of deionised water per $170 \mathrm{~g}$ of copolymer (approx.), while filtrating over a Büchner funnel. The copolymers were dried for at least three days at ambient temperature. The copolymers were processed with a Wiedmann 1212 melt viscosimeter equipped with an injection moulding device to produce test bars. The copolymers with $80 \mathrm{~mol} \% \mathrm{~S}$ were processed at $170{ }^{\circ} \mathrm{C}$, the copolymers with 50 mol $\% \mathrm{~S}$ at $140{ }^{\circ} \mathrm{C}$, and the copolymers with $25 \mathrm{~mol} \% \mathrm{~S}$ at $120^{\circ} \mathrm{C}$. The mould was kept at room temperature. This way of processing ensures that the particle structure resulting from the polymerization process is mostly destructed, leaving only structures directly resulting from the heterogeneity in chemical composition, i.e., the $\mathrm{CCD}$ or molecular weight.

Small tensile bars were manufactured according to ASTM D1708, because of the relatively small quantities of polymeric material available. Fracture toughness bars were manufactured with a self-constructed mould $\left(65^{*} 10^{*} 3 \mathrm{~mm}^{3}\right)$. The bars had a V-shaped notch of $2.54 \mathrm{~mm}$. A natural crack was generated by gently tapping on a razor blade placed in the notch tip. Tensile and fracture toughness bars were not annealed because 
especially the tensile bars would shrink too much, at annealing temperatures just above $\mathrm{T}_{\mathrm{g}}$. This means, however, that orientation in the bars could not be avoided. Orientation in the load axis may lead to an increase in material rigidity (Young's modulus), maximum stress, etc. Since all specimens had orientation, it was not possible to rule out the influence of orientation, but since all specimens had similar orientation, mutual comparison was probably not greatly affected.

\section{Analysis of Microstructure}

Size Exclusion Chromatography was used to determine the molecular weight distribution (MWD) of the polymers. The separation was performed on a chromatographic system (Waters Chromatography Division of Millipore) equipped with a refractive index detector. We used two Shodex linear columns (KF80M, length $30 \mathrm{~cm}$ ) in series. The eluent was tetrahydrofuran and an clution rate of $1 \mathrm{ml} / \mathrm{min}$ was used. For calculating the number and weight average molecular weights we applied universal calibration based on the average chemical compositions of the copolymers. The Mark-Houwink constants were taken from Ref. 19. The chemical composition distribution (CCD) of all copolymers examined was determined with gradient polymer elution chromatography. Separation was performed on a polar silica column (Rockland, Zorbax Sil). $\Lambda$ linear gradient was applied, starting with n-heptane (a non-solvent for all polymers), and ending with THF. The detector was a moving belt flame ionisation detector (Tracor 945 Universal FID Detector). The glass transition temperatures $\left(\mathrm{T}_{\mathrm{g}}\right)$ of the copolymers were determined with differential scanning calorimetry. The measurements were performed in air with a Perkin-Elmer DSC-7, in a temperature range of $-10^{\circ} \mathrm{C}$ to $125{ }^{\circ} \mathrm{C}$, and a heating rate of $20^{\circ} \mathrm{C} / \mathrm{min}$ was applied. Only second run results were used.

Scanning Electron Microscopy (SEM)

SEM was applied to examine the morphology of the fracture surfaces of copolymer fracture toughness bars. A Cambridge Stereoscan 2000 scanning electron microscope was used. The specimens were fractured at cryogenic temperatures to obtain a smooth surface with as few as possible deformation effects. The fracture surfaces were subsequently etched with an oxygen plasma and coated with a $\mathrm{Au} / \mathrm{Pd}$ layer to ensure conductivity. This process preferentially etches MA rich phases. 
Analysis of the Mechanical Properties

Tensile measurements were performed at room temperature on a Frank 81565 -IV tensile machine, with a crosshead speed of $5 \mathrm{~mm} / \mathrm{min}$. Elongation was measured with an Instron 2620-602 extensiometer. According to ASTM D1708 it is not permitted to determine Young's modulus of these tensile bars. However, since there was no other means to determine Young's modulus, we applied the above mentioned procedure allowing a relatively accurate mutual comparison of the tensile bars. Fracture toughness was measured with a Zwick Rel 1800 hydraulic tensile machine with a climate chamber. Crosshead speed was $10 \mathrm{~mm} / \mathrm{min}$, and the temperature was $\mathrm{kept}$ at $-25{ }^{\circ} \mathrm{C}$ to ensure a plane strain situation and brittle fracture of the specimens. The test was carried out according to the standard test of Williams and Cawood (Ref. 20), with three point bend specimens (also called SENB, single edge notehed bend).

\section{RESULTS}

In this section we will give the mechanical properties of the various copolymers. In general, the mechanical properties of the polymers depend greatly on their glass transition temperature $\left(\mathrm{T}_{\mathrm{g}}\right)$. The extremes in this ease are the $\mathrm{T}_{\mathrm{g}} \mathrm{s}$ of poly(styrene) and poly(methyl acrylate), ca 100 and $6{ }^{\circ} \mathrm{C}$ resp. When the $\mathrm{T}_{\mathrm{g}}$ is not much higher than the test temperature, the polymer will show visco-elastic behaviour, and measurements can depend on the crosshead speed in the tensile test. If the $T_{g}$ of the polymer (or of one of the phases in case of phase separation) is very close to the test temperature, it can be expected that the modulus and maximum stress will decrease, and the elongation will increase, as the behaviour will resemble that of a rubber. The extent of composition drift will affect the $T_{g}$ of the copolymers greatly, and therefore also the mechanical properties.

The copolymers are grouped according to their average chemical composition $\left(\mathrm{F}_{\mathrm{S}}\right)$ or way of preparation. The CCDs of all these copolymers are shown, and their molecular weights are given, as well as the glass transition temperatures. The following symbols are used to indicate how a copolymer was produced: BA for batch-wise, ST for semicontinuous under starved conditions ( 8 hour addition), and $\mathrm{OA}$ for semicontinuous with the optimal addition method; and in case of the 25 mol\% S copolymers, $\mathrm{CH}$ for the copolymers that were made in attempts to produce copolymers with pre-defined 
controlled heterogeneity. These symbols are followed by the average composition, e.g. BA80 is a copolymer made batch-wise, with an average composition of $80 \mathrm{~mol} \% \mathrm{~S}$.

Copolymers with $\mathrm{F}_{\mathrm{s}}=0.80$

As shown in the earlier publication (Ref. 18), copolymers with $F_{\mathrm{S}}=0.80$ are homogeneous with respect to chemical composition. This results from the fact that this composition is very close to the azeotropic composition. Hence composition drift is negligible, and the addition strategy has only a slight effect on homogeneity. In Fig. 1 the $\mathrm{CCD}$ are displayed. These CCDs give no reason to expect large differences in mechanical propertics. In Table 1a we displayed the weight average molecular weights.

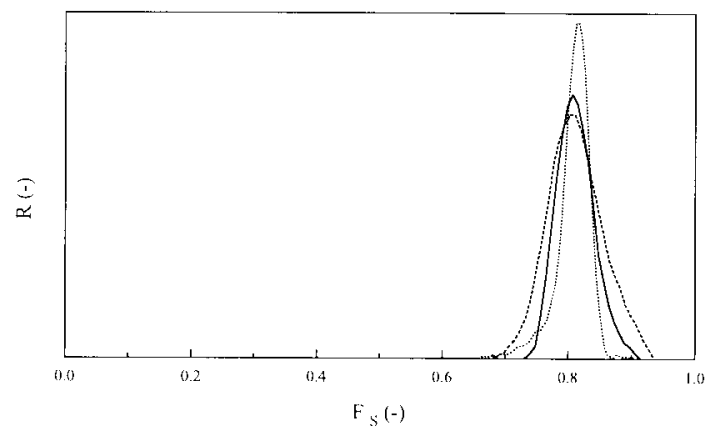

Fig. 1. The chemical composition distributions of copolymers with an average composition $F_{\mathrm{S}}-0.80$ :

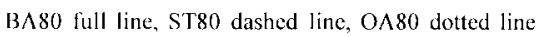

Table la. Molecular weights $\mathrm{M}_{\mathrm{w}}$ and glass transition temperatures $\mathrm{T}_{\mathrm{g}}$ of copolymers with $\mathrm{F}_{\mathrm{s}}=$ 0.80

\begin{tabular}{cccc}
\hline Product & $\mathrm{M}_{\mathrm{w}}$ & & $\mathrm{T}_{\mathrm{g}}$ \\
\cline { 2 - 3 } $\mathrm{kg} \cdot \mathrm{mol}^{-1}$ & & ${ }^{\circ} \mathrm{C}$ \\
\hline BA80 & 67 & & 82.2 \\
ST80 & 94 & & 81.0 \\
OA80 & 162 & & 87.8
\end{tabular}

The molecular weights of these polymers (Table la) are relatively small because we used a chain transfer agent in the recipes. It turns out that the molecular weights show 
some variation, whereas the CCDs do not differ significantly. We also measured the glass transition temperatures, and these are also shown in Table la. There seems to be some variation in $\mathrm{T}_{\mathrm{g}}$ for these copolymers in contrast to what would be expected from the CCDs. The reason for measuring the $\mathrm{T}_{\mathrm{g}}$ is mainly the fact it can be indicative of phase separation, which would lead to two glass transition regions. One could suggest that the high $\mathrm{T}_{g}$ of OA80 is a result of the higher molecular weight. In Table $1 \mathrm{~b}$ the mechanical properties are given ( $\mathrm{E}$ is Young's modulus, $\sigma_{\max }$ is maximum attainable stress, $\varepsilon_{b}$ is elongation at break, and $\mathrm{G}_{\mathrm{c}}$ is fracture toughness; in each case the standard deviation is given in brackets).

Table 1b. Mechanical properties (Young's modulus $\mathrm{E}$, maximum stress $\sigma_{\max }$, elongation at break $\varepsilon_{11}$, fracture toughness $G_{c}$ ) of the copolymers with $F_{s}=0.80$

\begin{tabular}{|c|c|c|c|c|}
\hline \multirow[t]{2}{*}{ Product } & E & $\sigma_{\max }$ & $\varepsilon_{\mathrm{b}}$ & $\mathrm{G}_{\mathrm{c}}$ \\
\hline & GPa & $\mathrm{MPa}$ & in $\%$ & $\mathrm{~J} \cdot \mathrm{m}^{-2}$ \\
\hline$B \wedge 80$ & $1.34(0.03)$ & $33.8(2.0)$ & $2.7(0.3)$ & $126(32)$ \\
\hline ST80 & $1.41(0.04)$ & $40.9(1.2)$ & $3.1(0.2)$ & $118(42)$ \\
\hline $0 \wedge 80$ & $1.44(0.08)$ & $65.6(0.6)$ & $8.4(0.1)$ & $357(26)$ \\
\hline
\end{tabular}

Since the CCDS of these polymers are very similar, the differences in mechanical properties must be a result of the differences in molecular weights. Maximum stress and elongation at break increase with increasing molecular weight. This is the expected inlluence of molecular weight. The Young's modulus is not affected by the difference in molecular weight, as expected.

Copolymers with $\mathrm{F}_{\mathrm{s}}=0.50$

The CCDs of these copolymers are displayed in Fig. 2 and the molecular weights and glass transition temperatures in Table $2 \mathrm{a}$.

It can be seen that the CCDs of ST50 and OA50 are homogeneous. But in contrast to what was found for BA80, BA50 is not quite homogeneous. This copolymer shows a main peak at a composition higher than 0.50 , and a tail extending to fractions far below 0.50 . The molecular weights vary somewhat and this makes it difficult to distinguish the effects of molecular weight and CCD. The mechanical properties are given in Table $2 b$. 


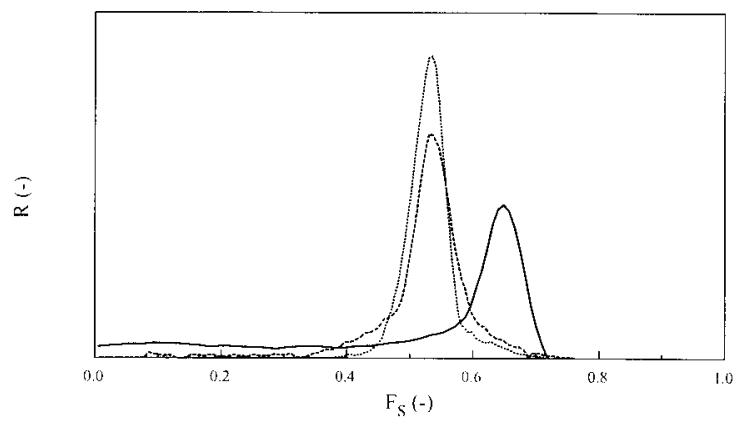

Fig, 2. The chemical composition distributions of copolymers with an average composition $F_{S}=0.50$ : BA50 full line, ST50 dashed line, OA50 dotted line

Table 2a. Molecular weights $M_{w}$ and glass transition temperatures $T_{g}$ of copolymers with $F_{s}=$ 0.50

\begin{tabular}{|c|c|c|}
\hline \multirow[t]{2}{*}{ Product } & $\mathrm{M}_{\mathrm{w}}$ & $\mathrm{T}_{\mathrm{z}}$ \\
\hline & $\mathrm{kg} \cdot \mathrm{mol}^{-1}$ & ${ }^{\circ} \mathrm{C}$ \\
\hline$B \wedge 50$ & 71 & 72.7 \\
\hline ST50 & 64 & 65.6 \\
\hline $0 \wedge 50$ & 34 & 62.8 \\
\hline
\end{tabular}

Table 2b. Mechanical properties (Young's modulus li, maximun stress $\sigma_{\max }$, elongation at break $\varepsilon_{1,}$, fracture toughness $\left(G_{c}\right)$ of the copolymers with $F_{s}=0.50$

\begin{tabular}{|c|c|c|c|c|}
\hline \multirow[t]{2}{*}{ Product } & $\mathrm{E}$ & $\sigma_{\max }$ & $\varepsilon_{\mathrm{p}}$ & $\mathrm{G}_{\mathrm{c}}$ \\
\hline & $\mathrm{GPa}$ & $\mathrm{MPa}$ & in $\%$ & $\mathrm{~J} \cdot \mathrm{m}^{-2}$ \\
\hline$B \wedge 50$ & $1.46(0.08)$ & $64.8(1.2)$ & $7.6(0.9)$ & $100(20)$ \\
\hline ST50 & $1.40(0.06)$ & $59.4(3.0)$ & $7.8(1.3)$ & $110(40)$ \\
\hline OA50 & $1.53(0.11)$ & $35.2(3.4)$ & $2.6(0.5)$ & $54(9.6)$ \\
\hline
\end{tabular}

Similarly to the results of the polymers with $F_{S}=0.80$, the maximum stress and the elongation at break increase with molecular weight, and Young's modulus is not affected. 
Copolymers with $\mathrm{F}_{\mathrm{S}}=0.25$

These copolymers generally show considerable composition drift (Refs. 6,18) and are therefore most likely to reveal an influence of composition drift on mechanical properties. We will first give the results of the copolymers that are made semicontinuously.

Because copolymers made under starved conditions are normally very homogeneous (Ref. 6), we looked at a copolymer made under starved conditions (ST25) which is heterogeneous with respect to $\mathrm{CCD}$ due to inhibition at the start of the monomer addition (Fig. 3). In addition, we looked at the properties of a copolymer that was produced with the optimal addition profile (O 25$)$. Another polymer (NA25) was made with a non-optimal addition profile, hence it is heterogeneous. Molecular weights, $\mathrm{T}_{\mathrm{g}}$, and mechanical properties are given in Tabs. $3 \mathrm{a}$. and $3 \mathrm{~b}$.

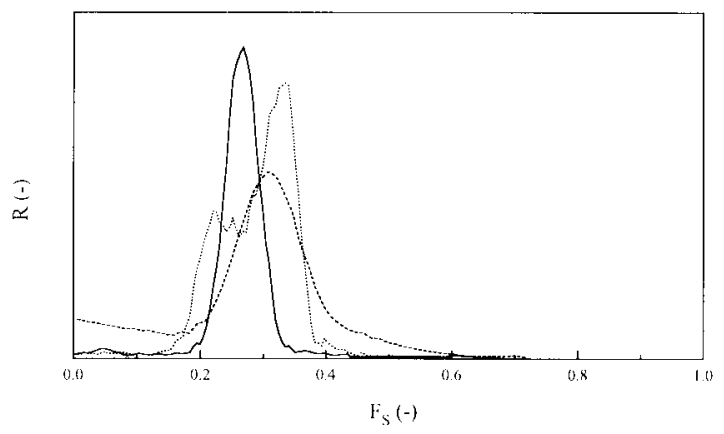

Pig. 3. The chemical composition distributions of semi-continuous copolymers with an average composition $F_{\mathrm{S}} \quad 0.25$ : OA25 full line, ST25 dashed line, NA25 dotted line

Table 3a. Molecular weights $\mathrm{M}_{\mathrm{w}}$ and glass transition temperatures $T_{g}$ of semicontinuous copolymers with $\mathrm{F}_{\mathrm{S}}=0.25$

\begin{tabular}{cccc}
\hline Product & $\mathrm{M}_{\mathrm{w}}$ & & $\mathrm{T}_{\mathrm{g}}$ \\
\cline { 2 - 3 } & $\mathrm{kg} \cdot \mathrm{mol}^{-1}$ & & ${ }^{\circ} \mathrm{C}$ \\
\hline OA25 & 14 & 41.7 \\
ST25 & 30 & \\
NA25 & 20 & $18.9 / 46.5$ \\
\hline
\end{tabular}


Table 3b. Mechanical properties (Young's modulus E, maximum stress $\sigma_{\max }$, elongation at break $\varepsilon_{b}$, fracture toughness $G_{c}$ ) of semicontinuous copolymers with $F_{s}=0.25$

\begin{tabular}{|c|c|c|c|c|}
\hline \multirow[t]{2}{*}{ Product } & E & $\sigma_{\max }$ & $\varepsilon_{\mathrm{b}}$ & $\mathrm{G}_{\mathrm{c}}$ \\
\hline & $\mathrm{GPa}$ & $\mathrm{MPa}$ & in $\%$ & $\mathrm{~J} \cdot \mathrm{m}^{-2}$ \\
\hline OA25 & $1.22(0.09)$ & $28.7(3.1)$ & $2.3(0.6)$ & $28(9.4)$ \\
\hline ST25 & $0.94(0.03)$ & $43.2(1.9)$ & $37.9(19)$ & $69(21)$ \\
\hline $\mathrm{NA} 25$ & $1.84(0.23)$ & $32.7(3.7)$ & $2.4(0.3)$ & $69(19)$ \\
\hline
\end{tabular}

Before we will discuss these copolymers, we will introduce some more copolymers with an average composition of $25 \mathrm{~mol} \% \mathrm{~S}$. These were made batch-wise. The CCDs of these are shown in Fig. 4.

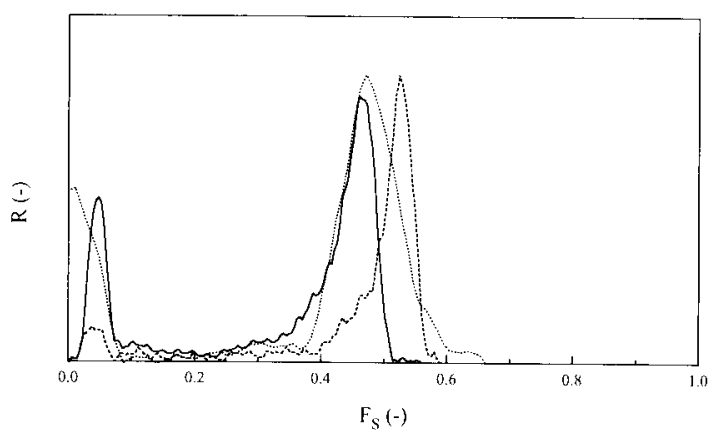

Fig. 4. The chemical composition distributions of batch copolymers with an average composition $F_{\mathrm{S}}=$ 0.25: BA25 full line, BA25* dashed line, MIX25 dotted line

BA25 is made with a recipe that is very similar to that of OA25 and ST25. It shows a typical bimodal CCD due to strong composition drift. BA25* was made with exactly the same recipe, the only difference being the absence of chain transfer agent. BA25 and BA25* show a remarkable difference in CCD. Theoretically, the CCDs of these polymers should be the same. However, the MA rich peak is much more pronounced in BA25 than in BA25*. The only difference in the recipes is the fact that in BA25* no chain transfer agent was used, which is why the molecular weight is so much higher (a factor of $c a 40$ ) (Table 4a). 
Table 4a. Molecular weights $\mathrm{M}_{\mathrm{w}}$ and glass transition temperatures $\mathrm{T}_{\mathrm{g}}$ of batch copolymers with $\mathrm{F}_{\mathrm{s}}=0.25$

\begin{tabular}{ccc}
\hline Product & $\mathrm{M}_{\mathrm{w}}$ & $\mathrm{T}_{\mathrm{g}}$ \\
\cline { 2 - 3 } $\mathrm{kg} \cdot \mathrm{mol}^{-1}$ & & ${ }^{\circ} \mathrm{C}$ \\
\hline BA25 & 23 & $16.7 / 56.7$ \\
BA25* & 840 & $15.4 / 59.8$ \\
MIX25 & 38 & $14.2 / 59.6$
\end{tabular}

We propose the following explanation for the apparent discrepancy between the CCDs of $\mathrm{B} \Lambda 25$ and $\mathrm{BA} 25^{*}$. It is known that acrylates give transfer to polymer, which leads to the formation of branched polymer chains (Ref. 21). In the last stage of the batch reaction, when all $S$ has been depleted, only $M \Lambda$ is reacting. It is very well possible that PMA (poly(methyl acrylate)) polymer radicals react with $M \Lambda$-units that are incorporated in the copolymer formed carlier. This then leads to branches of PM $\Lambda$ on the copolymer chains, which explains the high polydispersity of BA25* $(D=$ weight average molecular weight over number average molecular weight $=8$ ). Depending on the rates of transfer to (co)polymer and termination (true bimolecular or by transfer to monomer) a certain amount of the $M \Lambda$ that polymerizes in the last part of the reaction is bound to the copolymer chains. This means that not all MA forms free PMA chains. If a chain transfer agent (CTA) is present, as is the case in $\mathrm{BA} 25$, the rate of chain growth termination is increased, and the length of the PMA branches is reduced, because the rate of transfer to (co)polymer is not altered by the CTA. Thus in the presence of the ClA, the amount of PMA that is bound to copolymer is smaller than in the absence of CГA. Therefore, the peak that represents the free PMA-chains in the CCD $\left(\right.$ at $\left.F_{S}=0\right)$ is larger. The PMA that is bound to the copolymer contributes to the height of the copolymer peak. So with respect to composition drift the difference in CCD between $\mathrm{B} \wedge 25$ and $\mathrm{BA} 25^{*}$ is only apparent. MIX25 was made in an entirely different way. If one looks closely at the $\mathrm{CCD}$ of BA25 one can distinguish three regions: (1) a copolymer with an average composition of about $45 \mathrm{~mol} \% \mathrm{~S}$, (2) a (co)polymer mainly consisting of MA (this polymer is formed at the end of the batch reaction, when all $S$ has been depleted), and (3) copolymer with a composition ranging approximately from $5-10 \mathrm{~mol} \%$ to $40 \mathrm{~mol} \% \mathrm{~S}$. Of the last copolymer there is only a very small amount present, but because it has a broad range in composition it might act as a series of mutually compatibilizing compounds bridging the gap between the two phases that 
apparently exist in these batch polymers, as can be concluded from Table 4a. The (co)polymer mainly consisting of MA is rubbery. In rubber toughened materials, the rubber is present in small particles, but these can only toughen the material, if they are somehow bound to the matrix. To see whether the copolymer material with intermediate composition can actually serve to bind the rubber phase to the copolymer with $F_{\mathrm{s}}=45$ mol\%, we tried to make a polymer that resembles BA25, but that has no polymer with intermediate composition. MIX25 was therefore made by literally mixing two latices, one of a copolymer that was made semicontinuously under starved conditions, and the other of homopolymer PMA. The idea is that mixing these would result in a latex that had the same $\mathrm{CCD}$ as $\mathrm{BA} 25$, but without the copolymers of intermediate compositions in between the two large peaks in the CCD of BA25. Note that MIX25 has the same two $\mathrm{T}_{g} \mathrm{~s}$ as both other batch copolymers. On the basis of the $\mathrm{T}_{g}$ results one can only conclude that there is no significant difference in phase separation behaviour between MIX25 and $B \wedge 25$. The mechanical properties of $B \wedge 25, B \wedge 25^{*}$ and $M I X 25$ are given in Table $4 \mathrm{~b}$.

Table 4b. Mechanical properties (Young's modulus E, maximum stress $\sigma_{\text {max }}$, elongation at break $\varepsilon_{\mathrm{b}}$, fracture toughness $\mathrm{G}_{\mathrm{c}}$ ) of batch copolymers with $\mathrm{I}_{\mathrm{s}}=0.25$

\begin{tabular}{|c|c|c|c|c|}
\hline \multirow[t]{2}{*}{ Product } & $\mathrm{E}$ & $\sigma_{\max }$ & $\varepsilon_{1}$ & $\mathrm{G}_{\mathrm{c}}$ \\
\hline & Gla & $\mathrm{MPa}_{\mathrm{a}}$ & in $\%$ & $\mathrm{~J} \cdot \mathrm{m}^{-2}$ \\
\hline$B A 25$ & $0.55(0.04)$ & $24.2(1.1)$ & $79.2(8.3)$ & $94(31)$ \\
\hline BA $25^{*}$ & $1.19(0.33)$ & $32.1(2.4)$ & $57.2(8.1)$ & $260(60)$ \\
\hline $\mathrm{M} \times 25$ & $0.51(0.05)$ & $18.0(1.1)$ & $111(13)$ & $129(41)$ \\
\hline
\end{tabular}

\section{DISCUSSION}

In Fig. 5 we displayed the SEM micrographs of ST25, BA25, BA25*, and MIX25. These will be used in the discussions. We will discuss the mechanical properties in relation to the composition drift (using the CCDs, $\mathrm{T}_{\mathrm{g}} \mathrm{s}$, molecular weights and the SEM micrographs).

With help of the SEM micrographs we will show that the original particle structures are lost after processing, so that the mechanical properties we measured represent true bulk properties. 

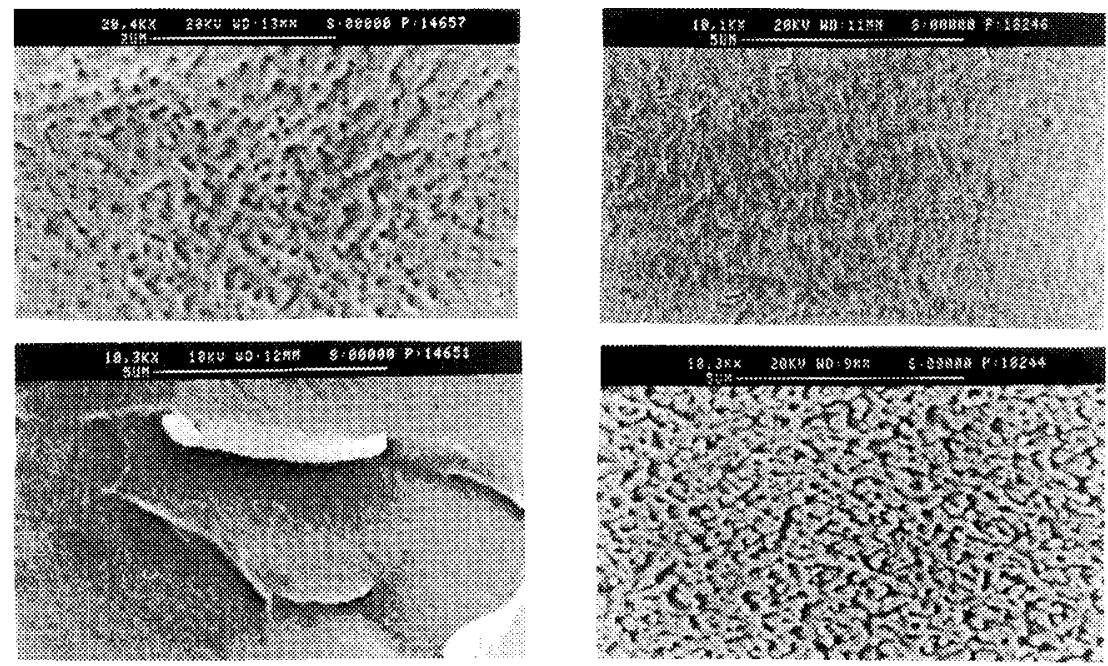

Fig. 5. SEM micrographs of heterogeneous copolymers: SI25 (top left), BA25 (top right), BA25* (bottom left), MIX25 (bottom right)

These SI:M micrographs are all of heterogeneous copolymers. The StiM micrograph of O^25 (not shown) shows a fracture surface without any indications of phase separation, which is expected on the basis of its honogeneity. If we look at the SEM micrograph of S125 (Fig. 5a), we can see a dispersed phase in a continuous phase. This is confirmed by the fact that DSC shows two glass transition regions. The dispersed phase is most likely the more $M A$-rich phase for three reasons: (1) the $\mathrm{M} \Lambda$-rich phase is the one that is most readily etched (the dark phase is the etched phase). (2) the volume fraction of the dispersed phase is smaller than the volume fraction of the continuous phase; the copolymer phase is larger than the PMA phase, (3) if the original particle structure were still partly present, the $M \Lambda$-rich phase would constitute the continuous phase, because this phase would be the shell in the original particle.

It has been shown belore (Ref. 22) that the particles of a batch emulsion copolymer made with a recipe exactly the same as that of $B \wedge 25$ have a core-shell structure, and that the shell consists of an MA-rich polymer that is formed in the last part of the reaction as a consequence of strong composition drift (Ref. 23). During the reaction of ST25, a composition drift similar to that of BA25 has occurred, and an MA-rich polymer was formed at the end of the reaction. This situation is very similar to what happens in a copolymerization of butyl acrylate (BA) and vinyl acetate (VAc) (Refs. 12,24-26). In that case in the last stages of the reaction a VAc-rich polymer is formed 
which forms a shell. Both MA and VAc are the more hydrophilic monomers which is another reason why phases rich in these monomers form the outer shell in the particles. On the basis of these comparisons it is clear that the original particle structure of ST25 is not the one that is present in the processed polymer material. The fact that phase inversion has occurred could be explained by the fact that during the processing the larger phase will become the continuous phase. BA25 (Fig. 5b) shows two cocontinuous phases, which unambiguously shows that the original particle structure is lost, as with ST25. We assume that the original particle structures of the other polymers are lost as well.

Chemically Homogeneous Copolymers

In Figs. 6 to 8 we displayed the various mechanical properties of the homogeneous copolymers as a function of molecular weight $\left(\mathrm{M}_{\mathrm{w}}\right)$ or average chemical composition $\left(F_{S}\right)$. For comparison we have included the data of the heterogeneous copolymers ST25, N $\Lambda 25, B A 25$, and MIX25 as well (open symbols; homogeneous copolymers: closed symbols), but these will be discussed in the next section.

lig. 6 shows $E$ of all these copolymers. It seems as if $E$ of the homogeneous copolymers is neither dependent on composition $\left(\mathrm{F}_{\mathrm{s}}\right)$ nor molecular weight. The latter observation has frequently been reported in literature. Note that the $\mathrm{T}_{\mathrm{g}} \mathrm{s}$ of all homogeneous copolymers are higher than the test temperatures, although that of OA25 is getting close to the test temperature.

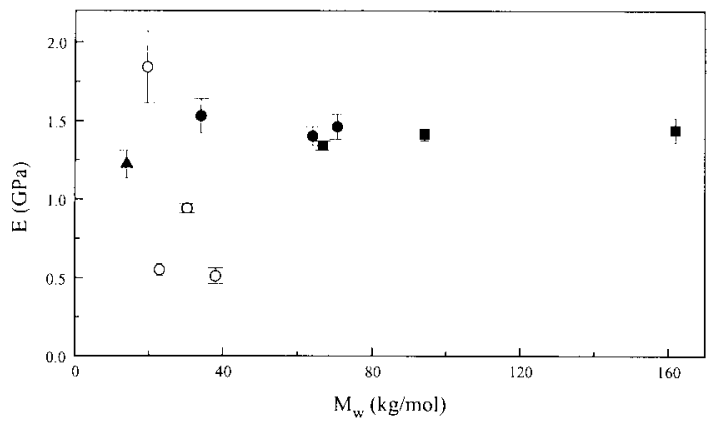

Fig. 6. Young's modulus of homogeneous (closed symbols: (ם) $F_{S} \cdots 0.80,(-) F_{S}=0.50,(4)$ OA25) and heterogeneous copolymers $(O)$ versus $M_{w}$ 
$\sigma_{\max }$ (Fig. 7) shows a different behaviour. If the data are plotted vs. $\mathbf{M}_{w}$ (Fig. 7a) it is clear that $\sigma_{\max }$ is strongly dependent on molecular weight. If the data are plotted against average chemical composition (Fig. 7b) we can conclude there is a only a very weak dependence upon composition bearing in mind the variation in $M_{w}$ the products show.
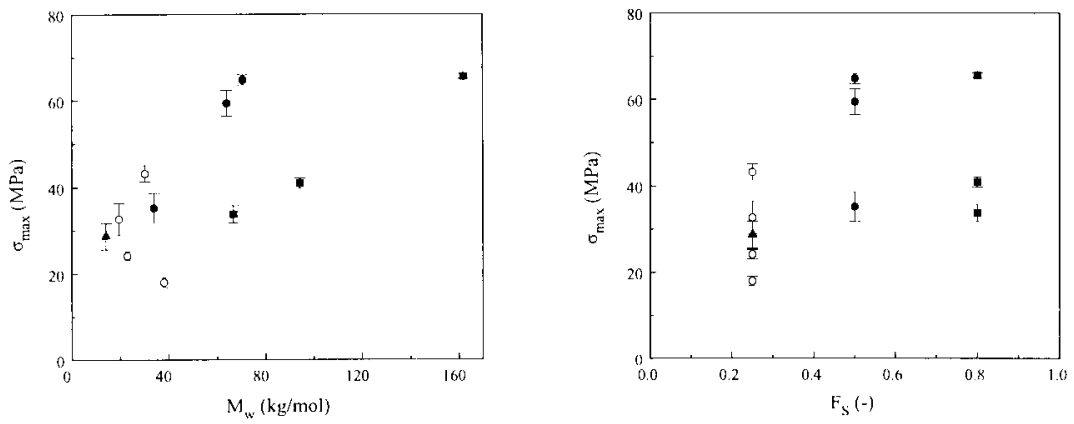

Fig. 7. Maximum stress of homogeneous (closed symbols:

$F_{S}=0.80,\left(-F_{S}=0.50,(\Delta) 0 A 25\right)$ and heterogeneous copolymers $(O)$, a) versus $M_{w}$, and b) versus $F_{s}$

$\varepsilon_{b}$ (lig. 8) shows a similar behaviour as $\sigma_{\max }$, although here the dependency on molecular weight is not as clear.
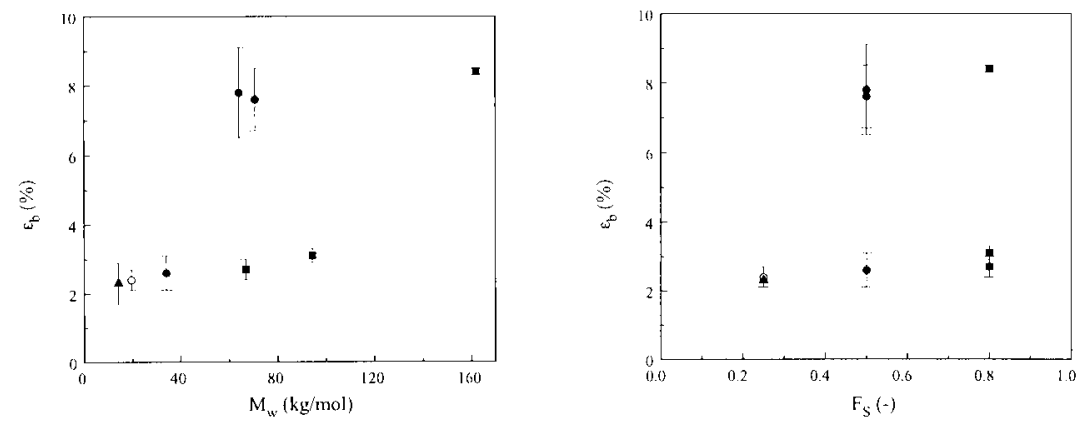

Fig. 8. Elongation at break of homogeneous (closed symbols:

(ש) $\mathrm{F}_{\mathrm{s}}-0.80$,

$\left.F_{\mathrm{s}}=0.50,(\Delta) \mathrm{OA} 25\right)$ and heterogeneous copolymers $(O)$, a) versus $M_{w}$, and b) versus $F_{s}$

Figs. 7a and $8 \mathrm{a}$ are remarkably comparable. Note that the maximum $\varepsilon_{\mathrm{b}}$ in this figure is $10 \%$, so that of the heterogeneous copolymers only $\mathrm{N} \Lambda 25$ is represented. In view of the large errors that are involved with the measurements of $G_{c}$ (possibly because it is difficult to maintain a plane strain situation) we will not draw any conclusions from these results. 
Do the results found for $\mathrm{E}, \sigma_{\max }$ and $\varepsilon_{\mathrm{b}}$ really indicate that the mechanical properties are independent of or weakly dependent on chemical composition in the case of S-MA copolymers? Since these copolymers were made by emulsion polymerization, it is conceivable that we are looking at an artefact: the copolymers could show a structure that is remnant of the original latex particle structurc, as is the case, for instance, with lilms cast from latices at relatively low temperatures. In those cases micrographs clearly show the existence of such structures (Ref. 27). However, we think this is not the case here. Firstly, the original particle structure is lost, as argued above. Sccondly, if the particle structure were not completely disrupted by the processing at high temperatures (well above $\mathrm{T}$ ), and the copolymer chains have not diffused across the particle boundaries, the mechanical properties could reflect the 'binding' between particles, rather than the 'binding' between polymer chains. If that were the case it would be unlikely that all homogeneous copolymers have the same value for $\mathrm{E}$, irrespective of their composition. Similarly a large variety in $\sigma_{\max }$ would be expected, rather than the weak dependence on composition and the almost linear dependence on molecular weight (generally, a linear dependence at relatively low molecular weights is found for true bulk polymers, i.e., polymers that were made by homogeneous polymerization (bulk or solution polymerization)). The curves of stress versus elongation (not shown) of all homogeneous copolymers point to britte failure, and of two $(B \wedge 50$ and $S T 50)$ to brittle lailure after some plastic yielding.

Gulbekian et al. (Ref. 28). have also looked at the mechanical properties of S-MA emulsion copolymers. These were all made batch-wise with $\mathrm{F}_{\mathrm{s}}$ ranging form approx. 0.09 to 0.22 . This means that these copolymers are very heterogencous. Gulbekian of al. report that the highest value for the modulus they have measured (at $\mathrm{F}_{\mathrm{s}} \approx 0.22$ ) is close to the range of values reported for poly(styrene). They expect that for increasing $S$ contents the modulus does not rise appreciably, but reaches a limiting value. This is in fact in accordance with the values found by us. Our values for the modulus are close to the maximum value of Gulbekian et al, and they do not vary in the range of $\mathrm{l}_{\mathrm{s}}=0.25$ 0.80. $\Lambda$ typical value of $\sigma_{\max }$ for poly(styrene) is $40 \mathrm{MPa}$. Gulbekian et al measured a highest value of ca $30 \mathrm{MPa}\left(\mathrm{at} \mathrm{F}_{\mathrm{s}} \approx 0.22\right.$ ), which is comparable to our average value at $F_{S}=0.25$, and not much lower that our values at $F_{S}=0.50$ and 0.80 . Admittedly, the dependence of $\sigma_{\max }$ on the molecular weight has to be taken into account, but unfortunately Gulbekian $e t \mathrm{al}$. do not report molecular weights. Our values for $\varepsilon_{\mathrm{b}}$ are $<$ $10 \%$ for $\mathrm{F}_{\mathrm{S}}=0.50$ or 0.80 , and for $\mathrm{OA} 25$. The value of Gulbekian et al. at $\mathrm{F}_{\mathrm{S}} \approx 0.22$ is 
in accordance with this.

Thus it seems that we can conclude that for homogeneous S-MA copolymers with $F_{S} \geq$ $0.25 \mathrm{E}$ is independent of $\mathrm{F}_{\mathrm{S}}$, and $\sigma_{\max }$ only weakly dependent. $\varepsilon_{\mathrm{b}}$ is always lower than $10 \%$ (brittle failure).

\section{Chemically Heterogeneous Copolymers}

We have seen that the properties of the homogeneous copolymers are not greatly affected by the chemical composition. From Figs. 6-8 (which include results from ST25. NA25, BA25, and MIX25) it is immediately clear that the situation is more complex with the heterogeneous copolymers. Since the heterogeneous copolymers show phase separation according to the DSC results, it is very likely that the mechanical properties are influenced by composition drift.

The stress versus elongation curves (not shown) indicate that all heterogeneous copolymers fail after plastic yiclding, in contrast to all homogeneous copolymers, which show brittle failure. This can be understood on the basis of the generally lower $T_{B} s$.

Fig. 6 shows that Young's moduli E of all heterogeneous copolymers are lower than the values of the homogeneous copolymers. This can be explained very well by the existence of two phases, one of which has a $T_{g}$ which is lower than the test temperature. This also explains why $\mathrm{E}$ of ST25 is higher than $\mathrm{E}$ of $\mathrm{BA} 25$ or MIX25. The last two have two co-continuous phases, ST25 has one continuous phase, and one dispersed phase, and the dispersed phase will not contribute much to E. The exception is NA25, which has an $E$ that is higher than $E$ of the homogeneous copolymers (it also shows brittle failure). According to DSC this polymer has only one phase, although its CCD looks quite heterogeneous. A similar situation is observed for $\sigma_{\max }$. The values are quite low, but again $\sigma_{\max }$ of ST25 is higher than those of BA25 and MIX25. The same explanation can be given here: co-continuous versus dispersed/continuous. With respect to the elongation at break NA25 again is not different from the homogeneous copolymers. From this one could conclude that although the CCD of NA25 is not as narrow as that of the homogeneous copolymers, it is apparently not broad enough to have any significant effect on the mechanical properties. There is, however, an enormous increase in $\varepsilon_{\mathrm{b}}$ for the other heterogeneous copolymers. In the case of BA25 
and MIX25 this increase results from the existence of two co-continuous phase, one of which is rubbery. Although $\mathrm{E}$ and $\sigma_{\max }$ of these products are roughly a factor of 2-2.5 lower than their homogeneous counterparts, the relative increase in $\varepsilon_{\mathrm{b}}$ is much larger. The increase in elongation at break of ST25 is probably caused by phase separation as well. However, in this case there is only one continuous phase and one dispersed phase (particles). The dispersed particles, which are rubbery at the test temperature, can act as craze initiators (Ref. 27) (multiple crazing). The stress versus elongation curve of ST25 indicates that it is a tough polymer, in contrast to the homogeneous OA25, which is brittle. Since the fracture toughness is measured at $-25^{\circ} \mathrm{C}$, the dispersed phase is not rubbery in fracture toughness tests, and the particles cannot act as craze initiators in these experiments.

From the above one can conclude that phase separation can have a huge effect on the mechanical properties, especially if the composition drift leads to a broad CCD. At this point there is not enough knowledge to predict what phases will develop, what their average chemical composition will be, what volume fraction they will have and whether the phases will be co-continuous or dispersed/continuous. If one looks at the structures of ST25, BA25 and MIX25, there is some rough trend: the CCD of ST25 shows a relatively small fraction of copolymer with a composition that deviates significantly from the main peak. In the case of BA25 and MIX25 there is a larger fraction of copolymer with a composition deviating significantly from the composition of the main peak. This may be taken as the explanation for the fact that the last two copolymers have two co-continuous phases. Ilowever, one should realize that more factors will play a role in this process.

The above mentioned results for $\mathrm{B} \Lambda 25$ and MIX25 show some differences. The small fraction of copolymer with a composition ranging from approximately $5-10 \mathrm{~mol} \%$ to 40 mol\% $\mathrm{S}$ has some effect on the mechanical properties. If we compare the SEM micrographs of these copolymers, we can see a large difference in structure. One could state that the copolymer with intermediate composition indeed has some compatibilizing effect; in MIX25 the phases are more clearly separated (although the difference according to the $T_{\mathrm{g}} \mathrm{s}$ is not significant), which is probably why $\varepsilon_{\mathrm{b}}$ is higher, and $\sigma_{\max }$ lower. In a very early publication by Kollinsky et al. (Ref. 29) it was shown for methyl methacrylate - butyl acrylate copolymers that only in copolymer mixtures where there are no gaps in the composition range (as in BA25) phase separation can be prevented to a certain extent. Unfortunately, as the two phases in BA25 are co-continuous, the intermediate copolymers cannot serve to improve any rubber-toughening effect. 
There is one polymer that we have left out of the discussion so far, BA25*. The reason for this is its high molecular weight. This high molecular weight explains the higher $\sigma_{\max }$ in comparison to BA25, MIX25, and ST25. Its $\varepsilon_{\mathrm{b}}$ is not as high as that of BA25. The reason for this can probably be found in the SEM micrograph of these copolymers. Where BA25 has two co-continuous phases, BA25* seems to have no second phase, although DSC gives two $T_{g} s$, both in excellent accordance with the values for both other batch copolymers. This could be explained by what we proposed as the explanation for the difference in CCD with BA25. Part of the PMA chains that are formed in the last stagc of the reaction, and which should constitute the second phase, are bound to the carlier formed copolymer chains, and hence cannot form a separate phase.

The above mentioned results indicate that control of the emulsion copolymerization as effectuated, for instance, in the case of the homogeneous copolymer OA25 leads to mechanical properties that are very different from the properties that result if the copolymerization is not controlled as with BA25. Note that the properties of the controlled copolymer are not necessarily better than those of the uncontrolled copolymer. The accidentally formed copolymer ST25 shows that intermediate situations (between homogeneous $(\mathrm{O} \wedge 25)$ and heterogeneous (BA25)) can occur readily. In principle it should be possible to make a copolymer with some desired property. In the next section we will treat a case where this was tried. Unfortunately, because of the kinetic nature of MA this did not succeed completely (Ref. 18). Nevertheless, in light of the relation between microstructure and mechanical properties, this section can serve as an illustration of the various possibilities that can in principle be achieved with controlled copolymerization as opposed to batch copolymerization.

Controlled Heterogencous Copolymers

In addition to the possibility to make homogeneous copolymers with semicontinuous copolymerization it should also be possible to make heterogeneous copolymers, i.e., copolymers that have a very broad rather than a very narrow CCD. In an earlier publication (Ref. 18) we showed results of attempts to make a copolymer with predefined broadness profile. The average composition of these copolymers was chosen to be $25 \mathrm{~mol} \% \mathrm{~S}$, so that it would be possible to compare them with the other copolymers with this average composition. Details of the reactions of these copolymers are given elsewhere (Ref. 18). In Fig. 9 the CCDs of three of these copolymers are given. $\mathrm{CH}$ 
stands for Controlled Heterogeneous, as opposed to the heterogeneous copolymers discussed above. Tabs. 5a. and 5b. show the results that were obtained with these copolymers.

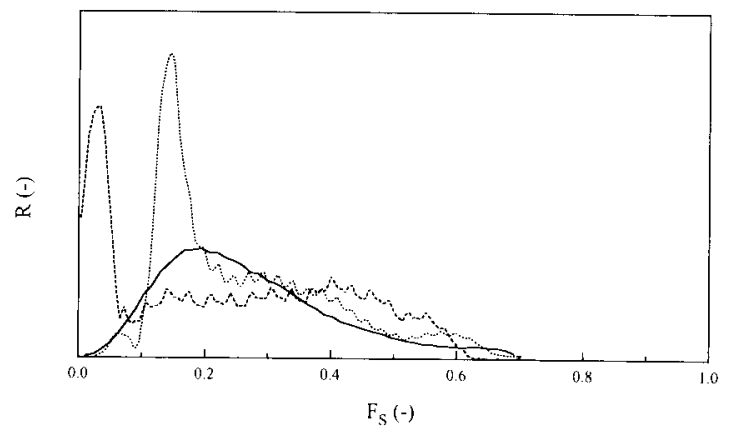

Fig. 9. Chemical composition distributions of controlled heterogeneous copolymers with an average composition $\mathrm{F}_{\mathrm{s}}=0.25: \mathrm{CH} 1$ full line, $\mathrm{CH} 2$ dashed line, $\mathrm{CH} 3$ dotted line

Table 5a. Molecular weights $M_{w}$ and glass transition temperatures $T_{b}$ of controlled heterogeneous copolymers with $\mathbf{F}_{\mathrm{S}}=0.25$

\begin{tabular}{|c|c|c|}
\hline Product & $\mathbf{M}_{\mathrm{w}}$ & $\mathrm{T}_{\mathrm{g}}$ \\
\hline & $\mathrm{kg} \cdot \mathrm{mol}^{-1}$ & ${ }^{\circ} \mathrm{C}$ \\
\hline ClII & 14 & 22.8 \\
\hline $\mathrm{CH} 2$ & 18 & 17.2 \\
\hline $\mathrm{CH} 3$ & 16 & 25.1 \\
\hline
\end{tabular}

Table 5b. Mechanical properties (Young's modulus $\mathrm{E}$, maximum stress $\sigma_{\max }$, elongation at break $\varepsilon_{\mathrm{b}}$, fracture toughness $\mathrm{G}_{\mathrm{c}}$ ) of controlled heterogeneous copolymers with $\mathrm{F}_{\mathrm{s}}=0.25$

\begin{tabular}{|c|c|c|c|c|}
\hline \multirow[t]{2}{*}{ Product } & E & $\sigma_{\max }$ & $\varepsilon_{\mathrm{b}}$ & $\mathrm{G}_{\mathrm{c}}$ \\
\hline & $\mathrm{GPa}$ & $\mathrm{MPa}$ & in $\%$ & $\mathrm{~J} \cdot \mathrm{m}^{-2}$ \\
\hline $\mathrm{CH} 1$ & $0.53(0.14)$ & $23.8(3.0)$ & $198(19)$ & $22(5.4)$ \\
\hline $\mathrm{CH} 2$ & $0.89(0.17)$ & $38.7(1.3)$ & $5.0(0.5)$ & $27(6.7)$ \\
\hline $\mathrm{CH} 3$ & $0.72(0.14)$ & $21.4(0.9)$ & $160(16)$ & $13(2.7)$ \\
\hline
\end{tabular}

The CCDs of these copolymers indicate a large heterogeneity. However, DSC only 
reveals one $\mathrm{T}_{\mathrm{g}}$ for these polymers. The SEM micrographs in Fig. 10 show that $\mathrm{CH} 1$ could have some phase separation (small dispersed particles), but this is not clear. CH3 shows no second phase and $\mathrm{CH} 2$ shows an anomalous morphology compared to all other products. The fact that $\mathrm{CH} 2$ showed only one $\mathrm{T}_{\mathrm{B}}$ can be misleading as the polymer that is not included in the peak at low $F_{S}$ has a composition that is spread out over a large range, so that any glass transition will be very vague and undetectable with DSC. The same applies in principle to $\mathrm{CH} 1$ and $\mathrm{CH} 3$ as well. The fact that the main peak in the $\mathrm{CCD}$ of $\mathrm{CH} 2$ has a low $\mathrm{F}_{\mathrm{S}}$ may explain why this polymer shows an anomalous morphology.
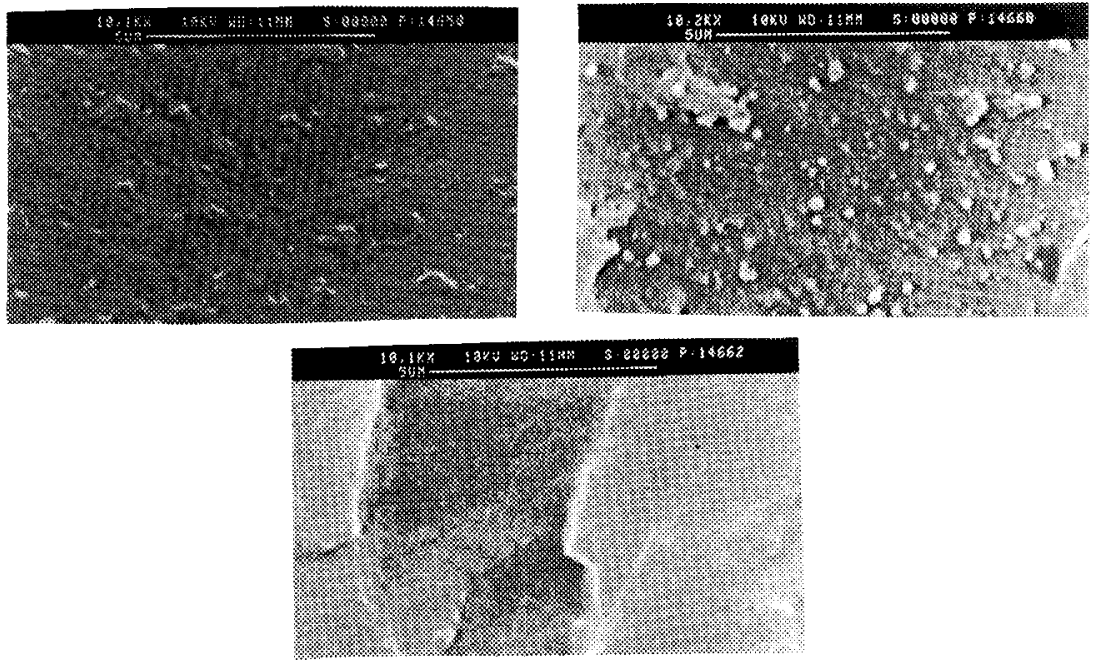

Fig. 10. SEM micrographs of controlled heterogeneous copolymers: CH1 (top left), CH2 (top right), $\mathrm{CH}$ (bottom)

The values for $\mathrm{E}$ of these copolymers are comparable to those of the other heterogeneous copolymers, and the $\sigma_{\max }$ are only slightly lower than those of the homogeneous copolymers. The most striking result from Table $5 \mathrm{a}$ is the very high $\varepsilon_{\mathrm{b}}$ of $\mathrm{CH} 1 \mathrm{l}$ and $\mathrm{CH} 3$ (even higher than the $\varepsilon_{\mathrm{b}}$ of BA25 and MIX25), and the very low $\varepsilon_{\mathrm{b}}$ of $\mathrm{CH} 2$. The continuous phase of $\mathrm{CH} 2$ has a relatively high $\mathrm{F}_{\mathrm{S}}$ and is probably not rubbery. The extremely high $\varepsilon_{b}$ of $\mathrm{CH} 1$ and $\mathrm{CH} 3$ is somewhat mysterious, if these really do not show phase separation. However, it has been shown (Ref. 29) that if a copolymer has a broad composition distribution it may seem that there is no phase separation, whereas close examination with transmission electron microscopy can reveal the existence of 
very small microphases that can not be detected with SEM. If this is the case in CH1 and $\mathrm{CH} 3$, then it could be the explanation for the high $\varepsilon_{b}$, but we have no further evidence for this. The stress versus elongation curves of $\mathrm{CH} 1$ and $\mathrm{CH} 3$ show plastic yielding, but $\mathrm{CH} 2$ seems to give brittle failure after some plastic yielding, resulting in the differences in elongation.

If all copolymers mentioned in this work are compared, one can conclude that the more heterogeneous the copolymer, the higher the elongation at break, the lower Young's modulus, and the lower the maximum stress, depending on the extent of phase separation. The heterogeneous copolymers all show plastic yiclding, whereas the homogeneous copolymers show brittle failure. The results of the controlled heterogeneous polymers illustrate that the control of composition drift can lead to very different properties depending on whether composition drift was prevented (homogeneous copolymers), not controlled (heterogeneous copolymers) or enhanced (controlled heterogeneous copolymers). To illustrate this point we plotted the values for $\mathrm{E}$ and $\varepsilon_{\mathrm{b}}$ of the copolymers with an average composition $\mathrm{F}_{\mathrm{S}}=0.25$ (Fig. 11). In this ligure one can clearly see the large variation in properties that can be attained by controlling microstructure.

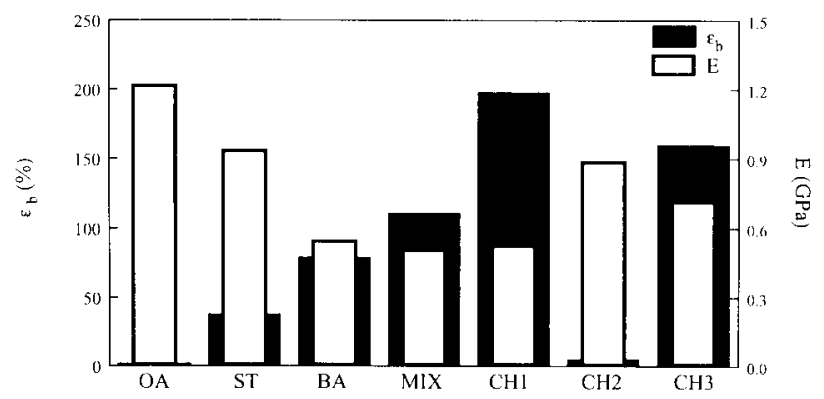

Fig. 11. Young's modulus (E) and elongation at break $\left(\varepsilon_{\mathrm{b}}\right)$ of heterogencous copolymers with $\mathrm{F}_{\mathrm{s}}=0.25$

\section{CONCLUSIONS}

It has been shown that composition drift in the emulsion copolymerization of styrene and methyl acrylate can have a very large influence on the mechanical bulk properties of the copolymers, as composition drift determines the copolymer microstructure. There is also a large effect of the molecular weight of these polymers. In the case of styrene - 
methyl acrylate copolymers that are homogeneous with respect to chemical composition it was found that Young's modulus is independent of chemical composition, and that maximum stress and elongation at break are only weakly dependent on chemical composition in the range of compositions investigated. Copolymers that are heterogeneous with respect to chemical composition have properties that are different from those of the homogeneous copolymers, and these properties can vary greatly. This can be mainly attributed to the existence of more than one phase, one of which is rubbery. It thus appears that the extent of control of composition drift (and thus copolymer microstructure) has a large influence on the final properties.

\section{ACKNOWLEDGLMENTS}

The authors wish to thank Wieb Kingma for the GPC work, Paul Cools and Matt Peters for the GPIC work, and Theo Tervoort for advice on the mechanical properties.

\section{REFERENCIS}

(1) J. Šn̆upárek, K. Kašpar, J. Appl. Polym. Sci. 26, 4081 (1981)

(2) T. Makgawinata, M.S. El-Aasser, A. Klein, J.W. Vanderhoff, J. Dispersion Sci. Technol. 5, 301 (1984)

(3) T.O. Broadhead, A.E. Hamielec, J.F. Maccregor, Makromol. (hem. Suppl. $\mathbf{1 0 / 1 1}, 105(1985)$

(4) (j. Arzamendi, J.M. Asua, J. Appl. Pol. Sci. 38, 2019 (1989)

(5) G. Arzamendi, J.M. Asua, Makromol. Chem. Macromol. Symp. 35/36, 249 $(1990)$

(6) G.H.J. Van Doremaele, H.A.S. Schoonbrood, J. Kurja, A.L. German, J. Appl Polym. Sci. 45, 957 (1992)

(7) K.C. L.ee, M.S. El-Aasser, J.W. Vanderhoff, J. Appl. Polym. Sci. 45, 2207 (1992)

(8) B. Li, B.W. Brooks, Polymer Int. 29, 41 (1992)

(9) J. Guillot, Makromol. Chem., Macromol. Symp. 35/36, 269 (1990)

(10) H. Kast, Makromol. Chem. Suppl. 10/11, 447 (1985) 
(11) M. Lambla, B. Schlund, E. Lazarus, Tha Pith, Makromol. Chem. Suppl. 10/11, 463 (1985)

(12) S.C. Misra, C. Pichot, M.S. El-Aasser, J.W. Vanderhoff, J. Polym. Sci., Part A: Polym Chem. 21, 2383 (1983)

(13) J.Y. Cavaille, C. Jourdan, J. Perez, Makromol. Chem, Macromol. Symp. 23, 411 (1989)

(14) M. Okubo, Makromol. Chem., Macromol. Symp. 35/36, 307 (1990)

(15) B. Schlund, J. Guillot, C. Pichot, Polymer 60, 1883 (1989)

(16) K.C. Lee, M.S. El-Aasser, J.W. Vanderhoff, I. Appl. Polym. Sci 45, 2221 (1992)

(17) D.R. Bassett, K.L. IIoy, in "Emulsion Polymers and Emulsion Polymerization", Lds. D.R. Bassett, A.E. Ilamielec, ACS Symp. Ser. 165, Washington D.C. (1981)

(18) II.A.S. Schoonbrood, H.A. Thijssen, II.M.G. Brouns, M. Peters, A.L. German, J. Appl. Polym. Sci. 49, 2029 (1993)

(19) T.P Davis, K.F. O'Driscoll, M.C. Piton, M.A. Winnik, Polym. Int 24, 65 (1991)

(20) J. G. Williams, M.I. Cawood, Polymer Testing 9, 15 (1990)

(21) P.A. Lovell, T.H. Shah, I. Heatley, in "Polymer Latexes, Preparation, ('haracterization, and Applications", Eds. E.S. Daniels, I.D. Sudol, M.S. EIAasser, ACS Symp. Ser. 492, Washington DC (1992)

(22) G.II.I Van Doremaele, Ph.D. Thesis (1990) ( $\Lambda$ ppendix $\Lambda$ ), Findhoven University of Technology, Eindhoven, The Netherlands

(23) G.II.I. Van Doremaele, F.IIJ.M. Geerts, H.A.S. Schoonbrood, J. Kurja, A.L. German, Polymer 33, 1914 (1992)

(24) S.C. Misra, C. Pichot, M.S. El-Aasser, J.W. Vanderhoff, J. Polym Sci., Part C: Polym. Lett. 17, 567 (1979)

(25) X.Z. Kong, C. Pichot, J. Guillot, Eur. Polym. J. 24, 485 (1988)

(26) J. Delgado, M.S. El-Aasser, C.A. Silebi, J.W. Vanderhoff, J. Polym. Sci, Part A: Polym. Chem. 28, 777 (1990)

(27) N. Sütterlin, Makromol. Chem., Suppl. 10/11, 403 (1985)

(28) E.V. Gulbekian, B.II. Quadri, G.E.J. Reynolds, Br. Polym. J. 2, 146 (1970)

(29) F. Kollinsky, G. Markert, Makromol. Chem. 121, 117 (1969) 